\title{
Pengembangan Metode Pembelajaran Mata Kuliah Tari Surakarta Dasar
}

\author{
Bambang Tri Atmadja* \\ Jurusan Tari Fakultas Seni Pertunjukan Institut Seni Indonesia Yogyakarta
}

\begin{abstract}
ABSTRACK
Metode pembelajaran mata kuliah Tari Surakarta Dasar di Jurusan Tari FSP ISI Yogyakarta mengalami perubahan paradigma, kurikulum yang memberlakukan pengurangan jumlah Sistem Kredit Semester (SKS) sesuai dengan Kurikulum Berbasis Kompetensi (KBK), berdampak tidak tercapainya isi muatan mata kuliah secara keseluruhan dan kualitas. Berdasarkan pengalaman lapangan, perlu adanya pembenahan metode pembelajaran dengan mempertimbangkan tingkat kualifikasi normatif atau standar pembelajaran. Hal ini dapat dilakukukan dengan cara memadatkan materi ajar rantaya I dan II menjadi satu materi yang mewakili keseluruhan dalam kesatuan materi rantaya putri, rantaya putra alus dan rantaya putra gagah. Pemadatan masing-masing materi tari dasar dilakukan agar peserta didik secara mudah belajar tarian bentuk pada jenjang mata kuliah berikutnya.
\end{abstract}

Kata kunci: rantaya, tari surakarta, kurikulum tari.

\section{Pendahuluan}

Di dalam proses belajar-mengajar dibutuhkan suatukomitmen untuksenantiasamengembangkan metode dengan mempertimbangkan sistem dan struktur materi pembelajaran. Jika materi itu berupa tari, maka sistem gerak harus mengacu pada jaringan unsur-unsur yang membentuk struktur tari. Para guru atau pengajar tari cenderung mengikuti metode mengajar yang dilakukan para pendahulunya, sehingga mereka kurang berani melakukan suatu perubahan metode pembelajaran yang bersifat efektif dan efisien dengan luaran yang optimal bagi peserta didik. Oleh karena itu, dipandang penting untuk melakukan suatu perubahan metode pembelajaran, terutama metode yang dapat diterapkan untuk semua orang dengan modal tari yang minimal.

Metode pembelajaran mata kuliah Tari Surakarta Dasar di Jurusan Tari FSP ISI Yogyakarta selama ini berjalan mengikuti para pengajar pendahulunya dengan kualifikasi 4 SKS. Umumnya diawali dengan penjelasan materi ajar yang dikategorikan ke dalam paket "Rantaya I dan II putra-putri” yang didesain agar peserta didik mampu menguasainya. Dalam pelaksanaan proses belajar-mengajar peserta didik langsung mendapat instruksi untuk melakukan "sikap" dan "gerak" dari setiap unsur dan motif gerak rantaya, baik rantaya I maupun rantaya II dengan terlebih dulu dosen memberi contoh unsur dan motif gerak. Materi rantaya I dan II dengan materi tari putra alus, putra gagah, dan putri, disepakati sebagai dasar-dasar gerak tari gaya Surakarta, sehingga penguasaan materi itu dipandang akan membentuk kualitas kepenarian.

Berjalannya metode pembelajaran ini tampaknya menghadapi suatu kendala ketika mata kuliah tari mengalami perubahan paradigma, yakni kebijakan pemberlakuan mata kuliah praktek daerah sebagai mata kuliah mayor dengan porsi optimal, sedang mata kuliah praktek daerah lain sebagai mata kuliah minor dengan porsi minimal. Dekonstruksijumlah besaranSKStentuberdampak pada kulitas kepenarian dengan penguasaan keterampilan teknik dan pengetahuan tari yang tinggi. Fenomena ini tampaknya berakibat pula pada praktek tari tradisi gaya Surakarta, atau gaya tari daerah lain yang diajarkan. Hal ini berdampak pada jabaran perkuliahan yang terkait dengan SKS, akibatnya tidak menghasilkan kualitas hasil yang optimal. Misalnya, terlalu banyak materi kuliah yang diberikan, sementara jam perkuliahan relatif tidak mencukupi. Gejala ini berjalan dari tahun ke tahun tanpa adanya perubahan metode pembelajaran.

Kebijakan perubahan kurikulum yang memberlakukan pengurangan jumlah SKS dari 4 SKS menjadi 3 SKS sesuai dengan Kurikulum Berbasis

\footnotetext{
Alamat korespondensi: Jurusan Tari ISI Yogyakarta. Jalan Parangtritis Km. 6,5 Sewon, Yogyakarta. Telepon: (0274) 375380.
} E-mail:bbgta@gmail.com 
Kompetensi (KBK), tampaknya berakibat pada proses belajar-mengajar di perguruan tinggi seni berjalan kurang sempurna alias banyak materi yang tidak diajarkan dan dilanjutkan pada mata kuliah Praktek Tari Surakarta I (mata kuliah lanjutan), sementara isian materi mata kuliah Praktek Tari Surakarta I berbeda. Dampak dari memberlakuan ini tentu saja tidak tercapainya isi muatan mata kuliah secara keseluruhan, sehingga terjadi kesemrawutan dalam proses belajarmengajar apalagi dengan pengajar yang berbeda. Materi tari bentuk sudah diajarkan, namun dengan penyesuaian mempercepat proses belajarmengajar atau materi ajar dipaksakan dengan waktu relatif lebih pendek, maka proses belajarmengajar berjalan tidak normal yang berdampak pada kualitas kesenimanan mahasiswa perguruan tinggi seni.

Berdasarkan pengalaman di lapangan ini, maka perlu adanya pembenahan metode pembelajaran dengan mempertimbangkan tingkat kualifikasi normatif atau standar pembelajaran. Metode yang dimaksud ialah memadatkan atau menyederhanakan materi ajar rantaya I dan II menjadi satu materi yang mewakili keseluruhan dalam kesatuan materi rantaya putri, rantaya putra alus dan rantaya putra gagah. Masing-masing materi tari dasar yang dipadatkan itu diharapkan peserta didik secara mudah belajar tarian bentuk pada jenjang mata kuliah berikutnya. Langkah yang harus dikembangkan ialah mendata unsur sikap dan unsur gerak dalam setiap motif gerak rantaya yang didasarkan pada pertimbangan kesatuan gerak tubuh (kepala, lengan dan tangan, badan, kaki).

Kebiasaan para pengajar tari Surakarta tidak berani merubah metode pembelajaran tari yang sudah diajarkan para pendahulunya merupakan faktorpenghambatkemajuan metodepembelajaran tari tradisi hingga dewasa ini. Oleh karena itu perlu adanya keberanian untuk merubah dalam artian menyempurnakan metode pembelajaran dengan mempelajari kelemahan dan kelebihan metode pembelajaran model lama. Cara mengajar rantaya tempo dulu cenderung memakan waktu yang cukup lama (kelemahannya), namun dengan belajar dalam tempo yang cukup lama peserta didik mampu menyerap ilmu tari dari gurunya secara lebih sempurna karena dapat berlatih secara terus-menerus. Ketika waktu belajar semakin dibatasi oleh kepentingan yang berbeda, maka diperlukan suatu perubahan dan inovasi metode pembelajaran dengan mempertimbangkan kepentingan peserta didik masa kini. Yang menjadi masalah sekarang adalah bagaimana mengembangkan metode pembelajaran tari dalam mata kuliah tari Surakarta Dasar.

\section{Metode Perancangan}

Istilah metode perancangan dipandang tepat, sebab yang dilaksanakan ialah kegiatan perancangan tari rantaya sebagai suatu bentuk pemadatan bentuk rantaya I dan II yang dipandang ada beberapa bentuk sikap dan gerak yang sama, sehingga dipandang penting untuk menyederhanakan agar tidak terjadi tumpang tindih atau suatu pengulangan gerak yang sama. Menurut istilah Susanne K. Langer bahwa suatu tari yang penting dan mendasar ialah bentuk fisik dan bentuk dinamik, sebagaimana dalam seni tari tradisi dikenal dengan konsep wiraga, wirama, dan wirasa. Pada teknik tari dasar gaya Surakarta seperti dalam mempelajari tari rantaya yang dutamakan terlebih dulu ialah wiraga (gerak tari) dan wirama (iringan). Kesepahaman antara gerak dan irama pada tingkat awal sangat penting, sebab tingkatan wirasa dilakukan untuk materi ajar pada klas tari yang kemudian.

Melaksanakan kegiatan perancangan ini diperlukan tahapan kegiatan, yaitu tahap pengumpulan data tentang tari rantaya I dan II serta gending iringan dengan memanfaatkan mata kuliah Teknik Tari Dasar Gaya Surakarta. Pengamatan terhadap materi tari rantaya di dalam kelas memiliki keuntungan tersendiri sebab sambil melihat mahasiswa menari, sekaligus dapat memperbaiki apabila mereka melakukan kesalahan dalam bergerak. Pengamatan tari rantaya dapat juga dilakukan melalui temuan dokumentasi foto dan video yang terkait langsung dengan objek perancangan.

S. Ngaliman seorang tokoh tari gaya Surakarta sering mengemukakan bahwa di dalam tari Jawa dikenal dengan istilah "beksa atau hambeksa", "lenggot bawa", dan "mataya". Beksa atau hambeksa berasal dari kata "hambek" dan "sa" atau "esa" atau "sawiji", yang artinya adalah semua gerak wiraga atau tingkah laku itu ditujukan kepada yang bersifat "esa" atau "Tuhan". Oleh karena itu, tari 
itu manifestasi dari gerak yang bersifat panembah kepada Tuhan Yang Esa, atau tari adalah gerakgerak indah dan ritmis yang dilandasi ketuhanan (religius). Sifat "hambek sawiji" ini, maka tari Jawa klasik selalu diawali dengan "sembahan" dan diakhiri dengan "sembahan" pula, yang dikandung maksud manembah kepada "Tuhan Yang Maha Esa”. Lenggot bawa, "lenggot" artinya gerak atau wiraga, sedang "bawa" artinya suara atau wirama. Jadi lenggot bawa berarti wiraga (badan) yang diiringi suara yang berirama atau lagu. Mataya berasal dari kata "ma" yang berarti "manunggal" dan "taya" yang artinya "dewa". Jadi "mataya" artinya "manunggal dengan dewa".

Di dalam tari tradisi gaya Surakarta, selain konsep adi luhung yang memiliki makna dan fungsi, serta nilai-nilai kehidupan yang mendasari konsep estetis, juga ada konsep lain yang lebih tertuju pada perwujudan tari tradisi yaitu bentuk/ pola, kualitas, karakter dan perbendaharaan gerak tertentu. (Santoso Prabowo,1990:84). Disebut terakhir ada dalam Serat Kridhawayangga (Sastra Kartika) yang menjadi acuan normatif bagi penerapan tari tradisi gaya Surakarta yang disebut sepuluh patrap beksa (sikap laku tari), yaitu Merak ngigel, Sata ngetapswiwi, Kukila tumiling, Branjangan ngumbara, Mundhing mangundha, Wreksa sol, Anggiri gora, Pucang kanginan, Sikatan met boga, dan Ngangrang bineda.

Merak ngigel (burung merak menari) dilakukan dengan cara: lutut dan siku direnggangkan ke samping, kedua telapak tangan didekatkan sejajar pusar, bahkan agak ke atas sedikit (dhengkul methethek, katimbangan methetheking sikut, epekepek kekalihipun kacaketaken sipat tuntunan (puser) radi kapara nginggil), digunakan untuk tari alus luruh (tua).

Sata ngetap swiwi (ayam mengepakkan sayap) dilakukan dengan cara perenggangan lutut ke samping hanya sekedarnya saja, telapak tangan juga sebatas tepat pada pusar (methetheking dhengkul lan sikut namung sawatawis, epek-epek tangan sipat puseran leres), digunakan untuk tari alus luruh (muda).

Kukila tumiling (burung menggelengkan kepala) merupakan perenggangan lutut atau siku ke samping dinamakan siguk jongjang (sekedar digeser), dengan cara sedikit merenggangkan lutut ke samping, dan perenggangan siku ke samping selebar-lebarnya. Kedua telapak tangan sejajar pusar bahkan agak sedikit ke bawah (methethekipun dhengkul kaliyan sikut winastan sihguk jongjang, tegesipun methetheking dhengkul sekedhik sanget; kosok wangsulipun sikut anggenipun methethek kapara langkung kathah. Epek-epek tangan kalih sipat puser kapara mangandhap), digunakan untuk tari alus lanyap (lincah).

Branjangan ngumbara (burung branjangan mengembara) berupa gerakan kerap bergetar dan menggerakkan tangan, pada pokoknya agak gesit dan selalu bertindak (kerep kedher lan ngebahaken asta, wosipun asemu rongeh sarwa tumandang), digunakan untuk tari gagah tandang.

Mundhing mangundha (kerbau menanduk) merupakan posisi berdiri kerap berhadapan dan menggerakkan kepala ke atas dan ke bawah. Jika berpandangan pasti bersamaan dengan anggukan kepala sakali (adgipun kerep aben ajeng tuwin ndhangak-ndhingklukaken sirah. Manawi ulatulatan temtu sareng lan manthuking sirah namun sapisan), digunakan untuk tari Bugis.

Wreksa sol (pohon tumbang tercabut akarnya) dilakukan dengan cara: pada waktu berdiri selalu bergerak pelan ke kanan dan ke kiri, serta sering menjatuhkan badan dibarengi gerakan kepala. Jika digambarkan, seperti tumbangnya pohon yang rindang, jika batang pohon jatuh baru diikuti jatuhnya rimbunan daun-daunnya (adegipun tansah hoyag lan kerep ndhawahaken badan kasarengan solahing sirah. Manawi kagambaraken badan kados dene ambruking wit ing ngrembuyung, manawi badan (wit) dhawah saweg katututan panggepyoking ronipun), digunakan untuk tari raksasa.

Anggirigora (seperti gunung yang menakutkan/ gemuruh menggemparkan) dilakukan dengan cara diam tak banyak bergerak, tegak dan kokohnya badan di dalam posisi berdiri bagaikan gunung yang menakutkan (kedah anteng, jejeg santosa ing adegipun), digunakan untuk tari gagah dugangan.

Pucang kanginan (nyiur tertiup angin) dilakukan dengan cara selalu bergerak tapi tersamar, perlahan-lahan seolah-olah tidak tampak (tansah obah nanging tamban, alon ing semu boten ngetawis), digunakan untuk tari putri.

Sikatan met boga (burung sikatan mencari makan) merupakan gerakan badan tidak teratur dan arah pandangan matanya dalam posisi berdiri (datan hanggp ing rongenipun badan lan polatan 
ing adegipun). Gerak seperti ini digunakan untuk tari kera.

Ngangrang bineda (semut ngangrang diusik) merupakan gerakan dimana sebentar-sebentar ibu jari kaki digerakkan ke depan seperti ulat jengkal. Maksudnya adalah agak doyong ke depan cara menegakkan tubuh dan arah pandangannya (ing sakedhap-sakedhap jempolan suku kalih hanguler kilan, tegesipun majeng adegipun badan dalah polatanipun).

Sepuluh patrap beksa ini sebagai dasar keterampilan merupakan prosedur awal untuk dikuasasi, namun sayangnya belum banyak diketahui dan diaplikasikan dalam proses pembelajaran teknik tari gaya Surakarta. Di samping itu juga diperlukan pemahaman tentang konsep Hastha Sawanda (delapan unsur yang menjadi satu kesatuan), terutama ditujukan untuk menentukan kriteria penari yang baik. Berikut ini konsep Hastha Sawanda: (1) Pacak ialah bentuk/pola dasar dan kualitas gerak tertentu yang ada hubungannya dengan karakter yang dibawakan; (2) Pancad ialah peralihan dari gerak yang satu ke gerak berikutnya dengan penuh perhitungan secara matang agar enak dilakukan dan dilihat; (3) Ulat ialah pandangan mata dan penggarapan ekspresi wajah sesuai dengan bentuk, kualitas, karakter peran yang dibawakan dan suasana yang diinginkan;
(4) Lulut ialah gerak yang sudah menyatu dengan penarinya seolah-olah tanpa dipikirkan lagi di luar kontrol pribadinya sebagai satu keutuhan tari; (5) Luwes ialah kualitas gerak yang sesuai dengan bentuk dan karakter peran yang dibawakan; (6) Wiled ialah variasi gerak yang dikembangkan berdasarkan kemampuan bawaan penarinya (ketrampilan, interpretasi, dan improvisasi); (7) Irama ialah menunjuk alur garap tari secara keseluruhan yang terkait hubungan gerak dengan iringannya (midak, nujah, nggandhul, sejajar, kontras, cepat, lambat, dan sebagainya); dan (8) Gendhing ialah penguasaan iringan tari yang di dalamnya menyangkut bentuk-bentuk gendhing, pola tabuhan, raga lagu, irama, laya (tempo), rasa seleh, kalimat lagu, dan juga penguasaan tembang maupun vokal (antawecana dan narasi).

Perpaduan sepuluh patrap beksa dan norma estetis hasthasawanda menjadi suatu kebutuhan sebagai dasar pembentukan kualitas keterampilan teknik gerak, terutama dalam pembentukan perwatakan gerak yang berlaku dalam tari tradisi gaya Surakarta. Pada dasarnya tari tradisi gaya Surakarta dibagi menjadi dua, yaitu tari putra dan tari putri. Namun demikian menurut karakterisasi gerak, maka tari tradisi gaya Surakarta terbagi atas beberapa kategori dengan skema sebagai berikut:

- luruh

a. Alus

- lanyap

b. Madyataya: aialah campuran antara gerakangerak alus dan dugangan

- kesatriyan (thelengan)

Tari Tradisi Jawa

1. Putra

c. Dugangan

d. Gecul

- agal/kasar

a. Alus (oyillurub)

2. Putri

b. Endel/kenes (lincah/lanyap)

c. Gecul

Contoh:

Alus luruh : Arjuna, Puntadewa, Abimbanyu

Lanyap : Kresna, Samba, Karna

Madyataya : Salya, Suyudana, para Begawan

Kasatriyan : Gatutkaca, Setyaki 
Tergolong karakter kasatriyan adalah "Kalang Kinantang" dan "Kambeng", untuk dugangan agal adalah bapang, bapang kasatriyan, dan bapang jeglong (raksasa). Putri alus ialah karakter tari Bedhaya, Srimpi, Dewi Sembadra, Dewi Sinta, sedang untuk putri endel ialah Srikandi, Mustakaweni, atau dalam tari Golek, Gambyong, dan Bondan.

Sejarah kehidupan tari tradisi Jawa (tari gaya Surakarta dan tari gaya Yogyakarta mengalami perkembangan yang mengagumkan, terutama perkembangan genre yang memiliki karakteristik struktur, sehingga jenis penyajian itu dapat dibedakan dengan jenis yang lain. Menurut genrenya, maka tari tradisi gaya Surakarta dibagi menjadi beberapa jenis penyajian, yaitu: bedhaya, srimpi, wireng, pethilan, gambyong, golek, wayang, bondan, dan topeng. Keseluruhan genre itu mengacu pada bentuk tari dasar rantaya (putri, putra alus dan dugangan), yang dalam perkembangannya pernah dipilahkan ke dalam rantaya I, II dan III. Tari dasar rantaya I motif geraknya masih sederhana yang lebih menekankan koordinasi sikap dan gerak tangan, badan, kepala dan tangan dengan iringan bentuk gending ketawang. Tari dasar rantaya II tata hubungan gerak tumpang tindih dan hirarkies dengan tingkat kesulitan lebih yang diiringi gending ladrang, sedang tari dasar rantaya III yang sudah dalam format tarian bentuk tanpa tema yang disebut beksan tandingan dengan kombinasi gending ketawang dan ladrang. Sesuai dengan fokus perancangan yaitu bentuk tari dasar putra gagah, maka berikut akan dijelaskan secara tata urutan geraknya.

\section{Pengembangan Metode Pembelajaran Tari Dasar Gaya Surakarta}

Pelaksanaan Kurikulum Berbasis Kompetensi terutama program S1 yang lebih mengutamakan teori dibanding praktek, sehingga pada perguruan tinggi seni yang seharusnya lebih mengutamakan aspek estetik dan artistik serta praktis ternyata dikurangi untuk lebih banyak porsi teoritis. Akibatnya, proses belajar-mengajar mata kuliah praktek di perguruan tinggi seni berjalan kurang optimal, yakni banyak materi yang tidak diajarkan atau dilanjutkan pada mata kuliah parktek berikutnya. Teknik tari Surakarta dasar yang biasanya diberikan bentuk ragam tari rantaya I dan II dengan tingkat kesulitan berbeda dengan nilai 4 SKS, tampaknya harus disesuaikan dengan diberlakukan bobot 3 SKS, sehingga membutuhkan evaluasi metode pembelajaran yang selama ini diberikan agar menghasilkan luaran yang baik untuk bekal belajar pada paket mata kuliah berikutnya. Jika materi tari bentuk sudah diajarkan, namun dengan penyesuaian mempercepat proses belajar-mengajar atau materi ajar dipaksakan dengan waktu relatif lebih pendek, maka proses belajar-mengajar berjalan tidak normal yang berdampak pada kualitas ketrampilan mahasiswa perguruan tinggi seni.

Berdasarkan pengalaman di lapangan ini, maka perlu adanya pembenahan metode pembelajaran dengan mempertimbangkan tingkat kualifikasi normatif atau standar pembelajaran. Salah satu metode pembelajaran ialah mengacu pada konsep konstruksi bangunan rumah, yaitu mulai dari pondasi dan komponen rumah yang berupa dinding dan tiang, baru kemudian asesoris rumah yang berupa hiasan interior rumah. Konsep ini tampaknya dapat diterapkan dalam metode pembelajaran tari dasar gaya Surakarta. Pemahaman tentang bentuk sikap dan gerak trapsilantaya, nikelwarti (jengkeng); kemudian pemahaman tentang sikap dan gerak tanjak, sabetan-besut, lumaksana, ombakbanyu-besut-srisig; bentuk tari kembangan dengan berbagai irama gerak. Keseluruhan bentuk unsur sikap dan gerak ini disusun kembali dengan mempertimbangkan kaidah-kaidah estetis dan normatif tari tradisi gaya Surakarta, yaitu mengacu pada patrap dan norma estetis dalam hasthasawandha. Tulisan ini difokuskan pada pengembangan metode prancangan untuk tari rantaya putra gagah.

Guna merancang keseluruhan bentuk tari rantaya dalam format baru ini tampaknya perlu untuk melakukan pemadatan bentuk tari dasar rantaya I dan II menjadi satu bentuk rantaya. Bentuk tari dasar rantaya yang baru ini harus mampu menjawab tingkat penguasan mahasiswa peserta didik. Selain pemadatan bentuk tari dasar rantaya itu, sebenarnya yang penting ialah sistem belajar mandiri. Untuk itu diperlukan alat bantu yang berupa buku panduan dan VCD panduan yang berisi secara detail dan terinci bentuk tari dasar rantaya. Alat bantu ini sangat membantu mahasiswa dalam mempelajari tari dasar rantaya, sebab belajar teknik tari dituntut untuk belajar 
mandiri secara berulang-ulang dan benar. Inovasi ilmu pengetahuan, teknologi dan seni diharapkan dapat membantu kelemahan sistem belajarmengajar konvesional yang berupa metode ceramah, diskusi, dan demontrasi secara klasikal.

Penyederhanaan materi ajar rantaya I dan II putra gagah menjadi satu materi yang mewakili keseluruhan dalam kesatuan materi rantaya putra gagah diharapkan dapat mempermudah cara belajar efektif dan hasil yang baik. Langkah yang harus dikembangkan ialah mendata unsur sikap dan unsur gerak dalam setiap motif gerak rantaya yang didasarkan pada pertimbangan kesatuan gerak tubuh (kepala, lengan dan tangan, badan, kaki). Sistem penggabungan rantaya I dan II didasarkan pada jumlah nilai hitungan dalam satuan motif gerak dan pola hitungan struktur gending yang mengiringi, misalnya untuk rantaya I biasanya dengan gending ketawang yang dalam setiap 1 gongan terdapat 2 kenong dan 1 kempul welo dan 1 kempul, sedang untuk rantaya II dengan gending ladrang yang dalam setiap gongan terdapat 4 kenong 1 kempul welo dan 3 kempul. Penyederhanaan rantaya I dan II tetap mempertimbangkan keutuhan sikap dan gerak unsur-unsur kepala, tangan, badan, dan kaki, sehingga didapatkan suatu struktur gerak baru dari pola/bentuk yang lama.

\section{Hasil Uji Coba Pengembangan Motede Pembelajaran}

Pengembangan uji coba metode pembelajaran ini telah diaplikasikan pada mata kuliah Repertoar Tari Surakarta Dasar yang diikuti oleh enam belas orang mahasiswa semester II dari berbagai daerah atau etnis. Mata kuliah ini merupakan kuliah praktek tari yang wajib diikuti oleh mahasiswa
Jurusan Tari sebagai dasar pembekalan untuk menempuh Repertoar tari Surakarta selanjutnya. Dalam uji coba ini dipilahkan ke dalam dua bagian yaitu penjelasan teoretis dan praktek. Uraian teoretis ini dijelaskan aturan normatif bagi penerapan tari tradisi gaya Surakarta yang disebut sepuluh patrap beksa dan delapan konsep tari tradisi Surakarta yang dikenal Hastha Sawandha.

Penerapan metode pembelajaran tari dasar rantaya dengan mengacu pada metode "konstruksi bangunan rumah" dan hasil pemadatan bentuk rantaya I dan II. Dalam pelaksanaan praktek Repertoar Tari Dasar Gaya Surakarta, mahasiswa melakukan secara bertahap dari susunan bentuk tari rantaya yang telah dipadatkan, yaitu mulai dari trapsila, jengkeng, tanjak, sabetan-besut, lumaksana kambeng, lumaksana laras kalangtinantang, lumaksana bapang jeglong, lumaksana bapang kasatriyan, sidangan sampir sampur wiled, sidangan kebjok sampur ngracik, engkrang, mbandul, ulapulap, ombak banyu-srisig, dan sembahan laras.

Keseluruhan bentuk dari tari dasar rantaya itu pada awalnya difokuskan pada bagian sembahan, lumaksana, gerak penghubung, dan sekaransekaran. Masing-masing bagian itu diujicobakan dengan menerapkan metode ceramah, metode demontrasi, diskusi, dan evaluasi untuk melihat tingkat kemajuan dan kemampuan mahasiswa. Untuk mengefektifkan kegiatan belajar mandiri, mahasiswa diberi pekerjaan rumah tentang materi yang diberikan dengan bantuan alat pembelajaran yang berupa VCD rantaya hasil pemadatan.

Berikut ini bentuk tari dasar rantaya hasil perubahan: 
Bambang Tri Atmadja, Pengembangan Metode Pembelajaran Mata Kuliah Tari

\begin{tabular}{|c|c|c|}
\hline No. & Uraian Gerak & Keterangan/Gambar \\
\hline 1. & $\begin{array}{l}\text { Ladrang Sari Wibowo Irama dadi (II) } \\
\text { Trapsilanoraga }\end{array}$ & \\
\hline 2. & Silantaya & \\
\hline 3. & Nyembah & \\
\hline 4. & Jengkeng & \\
\hline 5. & Nyembah jengkeng & \\
\hline 6. & Tanjak Purwantayaltanjak pertama & \\
\hline 7. & Hitungan pertama dalam gerak sabetan & \\
\hline
\end{tabular}




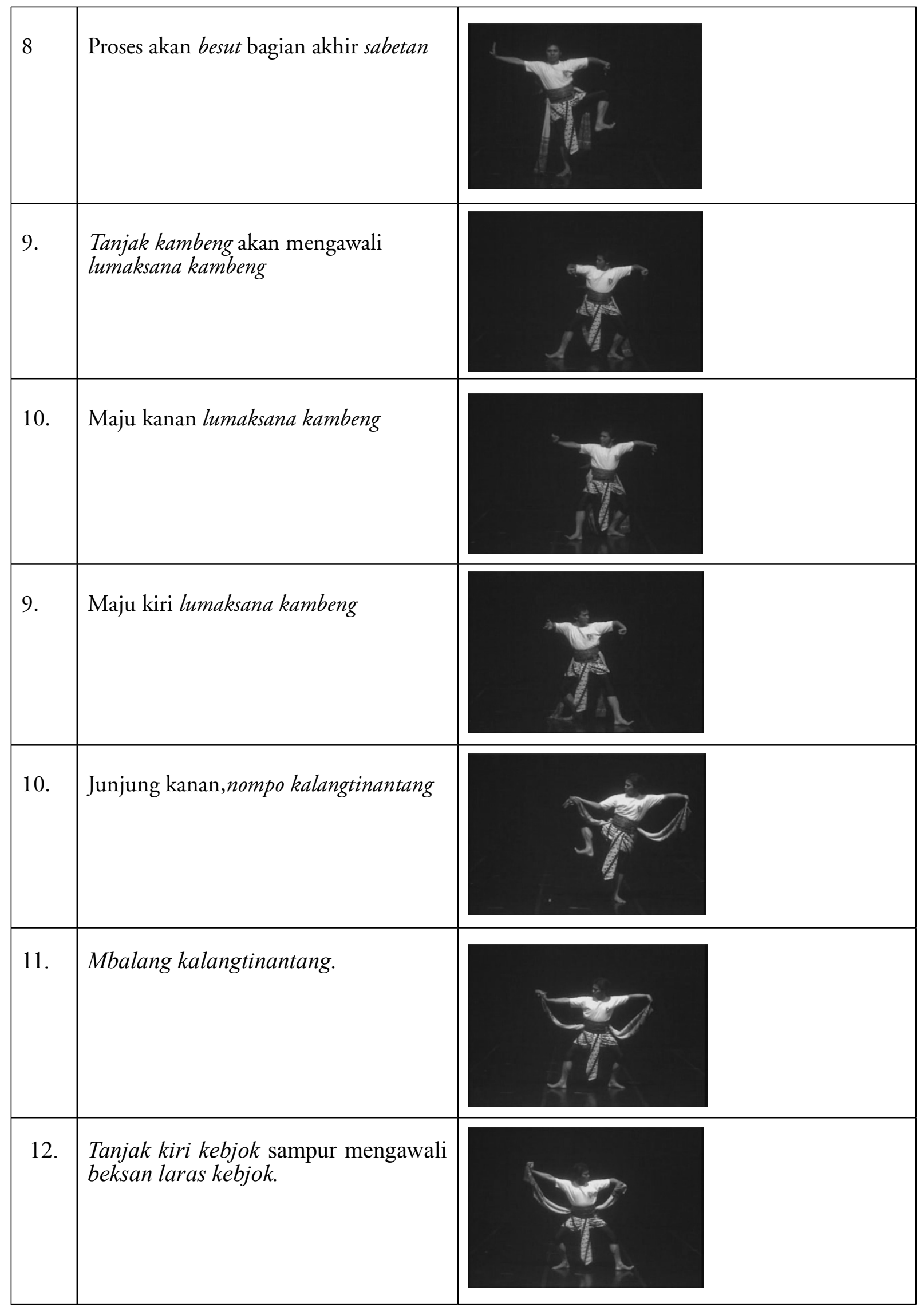




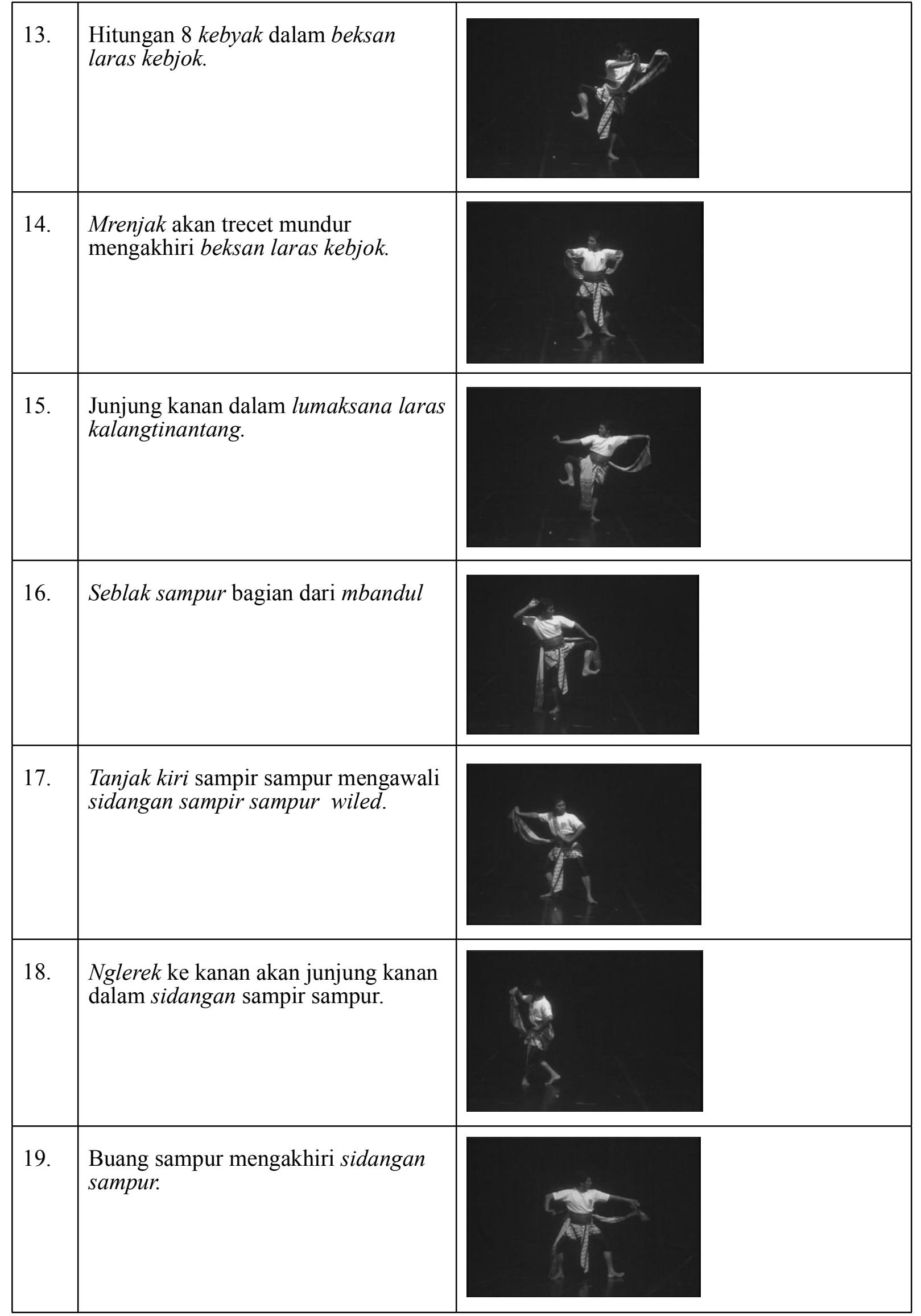




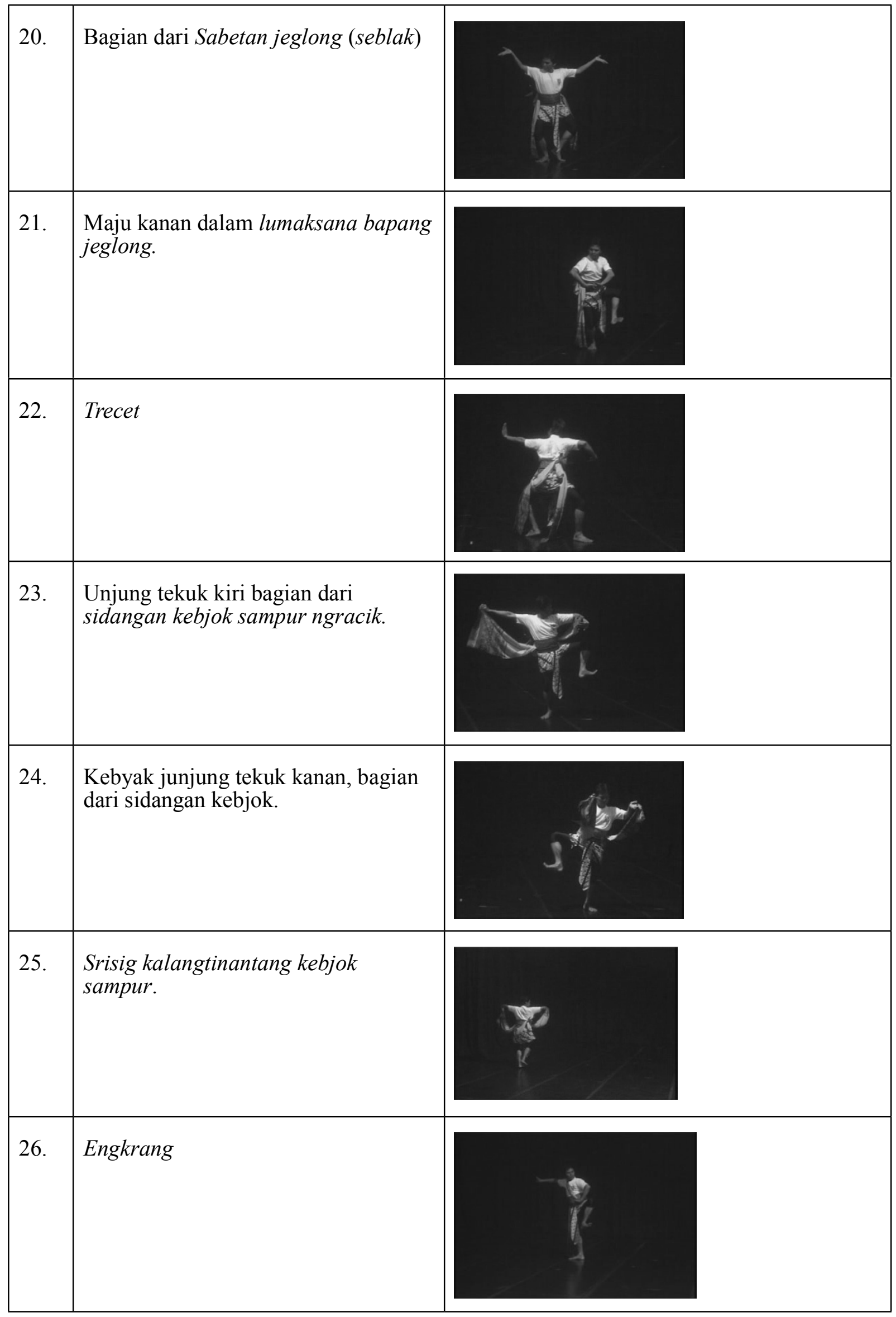




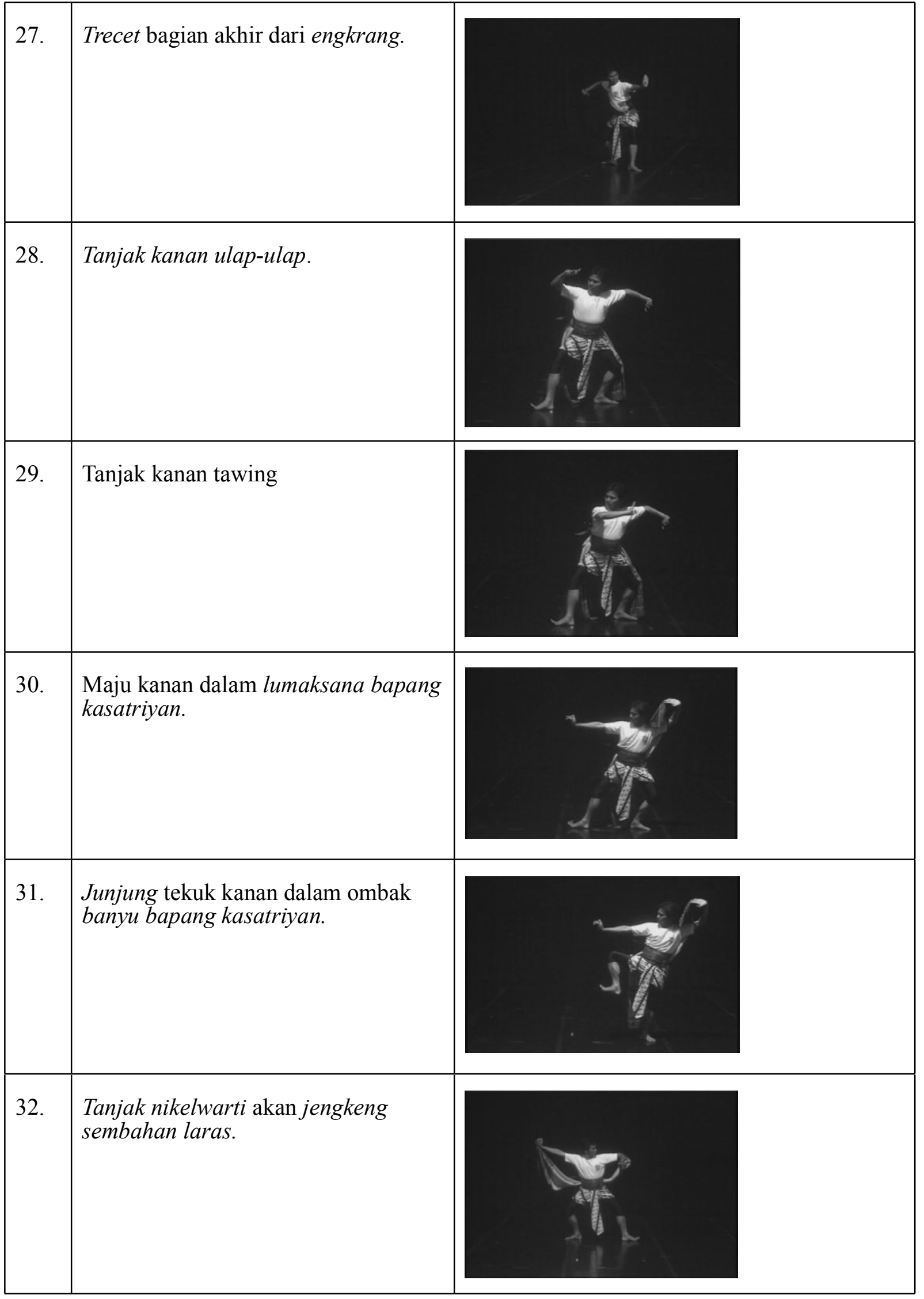




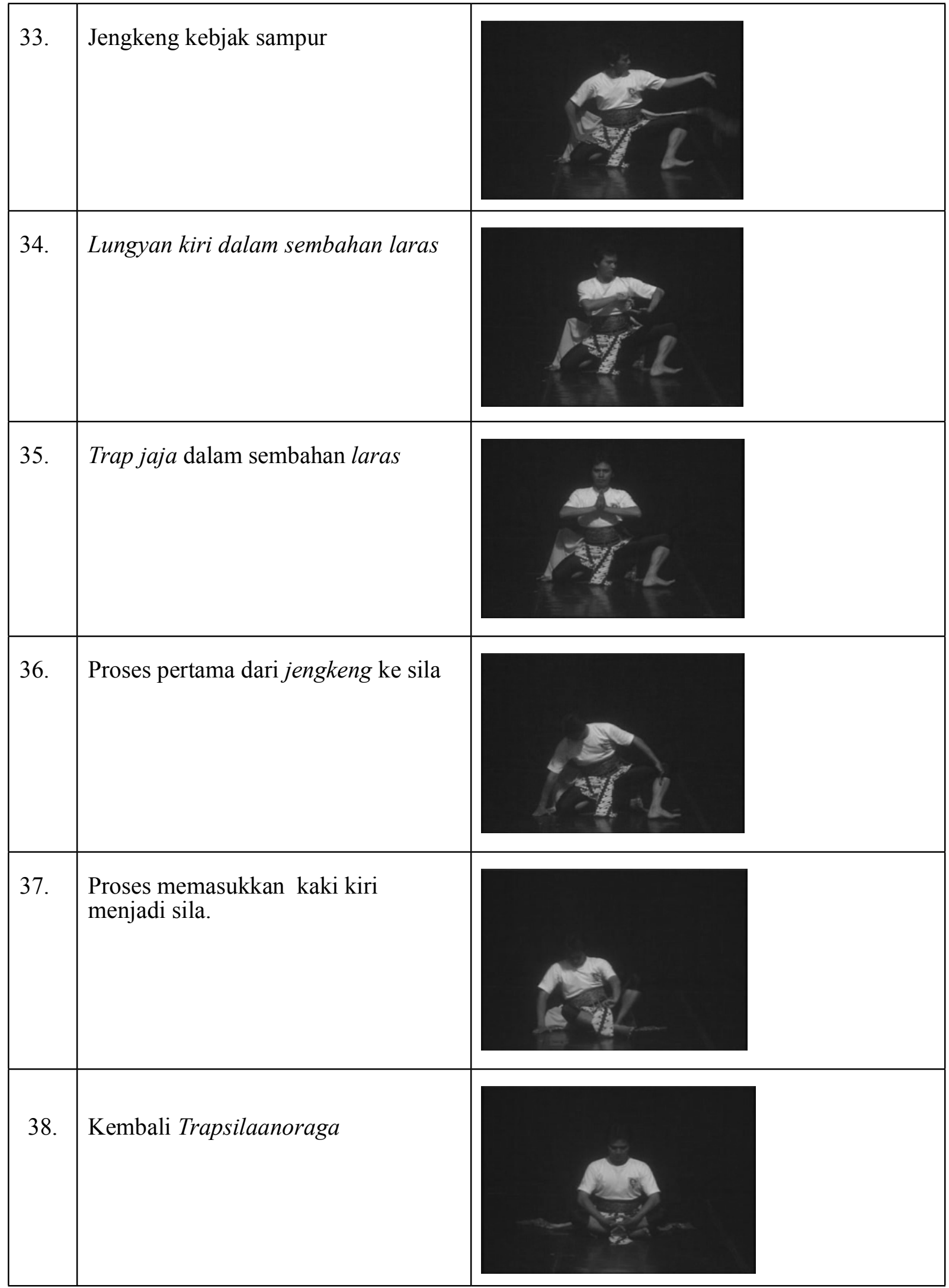




\section{Penutup}

Adanya pembenahan metode pembelajaran dengan mempertimbangkan tingkat kualifikasi normatif atau standar pembelajaran dipandang penting untuk meningkatkan kualitas anak didik. Salah satu metode pembelajaran yang dikembangkan ialah mengacu pada konsep konstruksi bangunan rumah, yaitu mulai dari pondasi dan komponen rumah yang berupa dinding dan tiang, baru kemudian asesoris rumah yang berupa hiasan interior rumah. Konsep ini tampaknya dapat diterapkan dalam metode pembelajaran tari dasar gaya Surakarta. Pemahaman tentang bentuk sikap dan gerak trapsilantaya, nikelwarti (jengkeng); kemudian pemahaman tentang sikap dan gerak tanjak, sabetan-besut, lumaksana, ombak banyu-besut-srisig; bentuk tari kembangan dengan berbagai irama gerak. Keseluruhan bentuk unsur sikap dan gerak ini disusun kembali dengan mempertimbangkan kaidah-kaidah estetis dan normatif tari tradisi gaya Surakarta, yaitu mengacu pada patrap dan norma estetis dalam hastha sawandha.

Metode pembelajaran ini merupakan alternatif yang dipandang efektif dan efisien dalam proses belajar-mengajar, sehingga anak didik mampu belajar mandiri dengan alat bantu buku panduan dan VCD Repertoar Tari Surakarta Dasar. Kedua sumber belajar aktif itu secara langsung mampu melakukan interaksi aktif, baik secara personal maupun secara kelompok, sebab mahasiswa dapat belajar secara kritis terhadap objek pembelajaran dan mendiskusikannya dengan mahasiswa lain untuk meningkatkan kualitasnya.

\section{Kepustakaan}

Brakel Papenhuyzen, Clara. 1991. Seni Tari Jawa Tradisi Surakarta dan Peristilahannya. Jakarta: ILDEP-RUL.

Dharmamulya, Sukirman, R.M.1982. Ng. Wignyahambekso: Hasil Karya dan Pengabdiannya. Jakarta: Departemen Pendidikan dan Kebudayaan,

Direktorat Sejarah dan Nilai Tradisional, Proyek Inventarisasi dan Dokumentasi Sejarah Nasional.
Harjoprasonto, Soemardjo. 1997. Bunga Rampai Seni Tari Solo. Jakarta: Taman Mini Indonesia Indah.

Humardani,S.D. 1975. "Masalah-Masalah dasar Pengembangan Seni Tradisi". Kertas kerja untuk bahan latihan tenaga pengajar Akademi Seni Karawitan Indonesia Surakarta.

Ngaliman, S. 1990. "Hubungan Tari dan Karawitan". Makalah untuk Penataran Pelatih Tari Daerah Jawa, diselenggarakan oleh Pusat Pelatihan Kesenian, Dinas Kebudayaan DKI Jakarta, Proyek Peningkatan Mutu Pelatih Seni Budaya.

.2008. "Rantaya II". Makalah untuk Penataran Pelatih Tari Daerah

Jawa, diselenggarakan Pusat Latihan Kesenian, Dinas Kebudayaan DKI Jakarta, Proyek Peningkatan Mutu Pelatih Seni Budaya.

2008. "Tari Pamungkas Sebagai Perkembangan Dari Tari Klasik”. Makalah untuk Penataran Pelatih Tari Daerah Jawa, diselenggarakan Pusat Latihan Kesenian, Dinas Kebudayaan DKI Jakarta, Proyek Peningkatan Mutu Pelatih Seni Budaya.

. 2008. "Tari Kridhawarastra Sebagai Perkembangan Dari Tari Lawung". Makalah untuk Penataran Pelatih Tari Daerah Jawa diselenggarakan Pusat Latihan Kesenian, Dinas Kebudayaan DKI Jakarta, Proyek Peningkatan Mutu Pelatih Seni Budaya.

.2008." Rantaya ISebagai Materi Dasar

Tari Surakarta". Makalah untuk Penataran Pelatih Tari Daerah Jawa, diselenggarakan Pusat Latihan Kesenian, Dinas Kebudayaan DKI Jakarta, Proyek Peningkatan Mutu Pelatih Seni Budaya.

Nursyahid P, Much.1987. "S. Ngaliman Tjondropangrawit: Empu Tari Tradisi Sing Bola-Bali Nganglang Jagad," dalam Jaya Baya no.9, tanggal 25 Oktober.

Prabawa, Wahyu Santasa.1990. ”Bedhaya Anglir Mendung: Monumen Perjuangan.

Mangkunegara I 1757-1988”. Tesis S-2 Program Studi Sejarah, Jurusan Ilmu-Ilmu Humaniora, Fakultas Pasca Sarjana Universitas Gadjahmada Yogyakarta. 